space and time // From huts to houses. Transformations of ancient societies // Stockholm. 2001. P. 11-21.

44. Stordeur D., Abbes F., Du PPNA au PPNB : mise en lumiere d'une phase de transition a Jerf el Ahmar (Syrie) // Bulletin de la Societe prehistorique française. T. 99, n3. 2002. P. 563-595.

45. Kobayashi T., Kaner S., \& Nakamura O. Jomon reflections. Forager life and culture in the prehistoric Japanese archipelago. Oxford: Oxbow Books, 2004. 256 p.

46. Борзунов В.А., Кирюшин Ю.Ф., Матющенко В.И. Поселения и жилища эпох камня и бронзы Зауралья и Западной Сибири // Памятники древней культуры Урала и Западной Сибири.//Екатеринбург, 1993. C. 4-45.

47. Thomas J. Mesolithic-Neolithic transitions in Britain: from essence to inhabitation // The MesolithicNeolithic Transition in Europe. London: British Academy, 2007. P. 423-439.

48. Kriiska A. The beginning of farming in the Eastern Baltic // The east European plain on the eve of agriculture. Oxford: Oxbow Books, 2009. C. 159-179.
49. Ozdogan M. A new look at the introduction of the Neolithic way of life in Southern Europe. Changing paradigms of the expansion of the Neolithic way of life // Documenta Praehistorica XLI. 2014. P. 33-49.

50. Nordqvist K. and Kriiska A. Towards Neolithisation. The Mesolithic-Neolithic transition in the central area of the eastern part of the Baltic Sea // Archaeology and History of the Baltic 8. 2015. P. 537-556.

51. Ozdogan M. The expantion of the neolithic way of life: What we know and what we do not know // How did farming reach Europe? Anatolian-European relations from the second half of the 7th through the first half of the 6th millennium Cal BC. Proceedings of the International Workshop. Istanbul, 20-22 May 2004. BYZAS 2. 2005. P. 13-27.

52. Mlekuz D. The Neolithic Year // The Oxford Handbook of Neolithic Europe. Oxford, 2014. P. 447-461.

53. Mlekuz D. Bodies, houses and gardens: rhythm analysis of Neolithic life-ways // Documenta Praehistorica XXXVII. 2010. P. 193-204.

\title{
THE EARLIEST DWELLINGS OF THE STONE AGE IN SMOLENSK AND PSKOV REGIONS OF RUSSIA
}

(C) 2016

\section{I.Yu. Khrustaleva, junior researcher of Eastern Europe and Siberia Archaeology Department} The State Hermitage Museum, Saint Petersburg (Russia)

Abstract. The following paper analyzes the ancient building traditions of the upper Dvina basin. The paper deals with the earliest dwellings in the region, found on the base layer of seasonal Stone Age settlements of the Smolensk and Pskov regions: Serteya 3-3 Serteya X, Serteya XIV, Rudnya Serteyskaya and settlement Uzmen. During the excavation, these materials were isolated in a single layer of Early Neolithic Serteyskaja culture. As a result of spatial analysis of the dwellings remains on the settlements Serteya X, Serteya XIV, and studying findings correlated with these structures, the existence of Mesolithic buildings were allocate and justified within this layer. An analysis of the plans and remains of structures revealed the features of the Mesolithic - Early Neolithic transition, manifested in dwellings form changing: the transition from round to oval and subrectangular in plan that also noted by the Stone Age archaeologists, not only for the territories of the forest zone. Such changes are unlikely to be random, and probably can be considered as Neolitization element, but these assumptions still require further research and evidence.

Keywords: Mesolithic; Early Neolithic; Serteyskaya Early Neolithic Culture; North-West Russia; Smolensk region; Pskov region; dwellings; the buildings; Neolithization; seasonal settlements; sites; settlements in the sandy sediments; the relative chronology.

УДК 902.903'12

\section{К ИЗУЧЕНИЮ РЫБОЛОВСТВА В ЭНЕОЛИТЕ ЛЕСОСТЕПНОГО ПОВОЛЖЬЯ (ПО МАТЕРИАЛАМ РАСКОПОК ПОСЕЛЕНИЯ ЛЕБЯЖИНКА VІ В 2013-2014 ГГ.)} (C) 2016

А.И. Королев, кандидат исторических наук, декан исторического факультета, доцент кафедры отечественной истории и археологии

А.А. Шалапинин, кандидат исторических наук, научный сотрудник научно-исследовательской части Самарский государственный социально-педагогический университет, Самара (Россия)

Е.Ю. Яниш, кандидат биологических наук, младший научный сотрудник отдела мониторинга и охраны животного мира Институт зоологии им. И.И. Шмальгаузена, Киев (Украина)

Аннотация. В статье рассматриваются орудия рыбного промысла и кости рыб поселения Лебяжинка VI лесостепного Поволжья эпохи энеолита в рамках комплексного исследования памятника. В заполнении котлованов жилищ выявлена керамика с «внутренним ребром», каменные, костяные орудия, кости животных, черепах, птиц и рыб. Особое значение поселения заключается в возможности изучать их как один комплекс. Целью данной статьи является анализ орудий лова и охоты на рыбу и костей рыб. К орудиям охоты относятся костяные гарпуны с одним, двумя и многими зубцами, расположенными по одной стороне. Костяные рыболовные крючки двух типов: цельные крючки-блесна и составные. Определены типологические особенности орудий лова, выполнены количественные, видовые, возрастные, размерные характеристики рыб. Основными были 
щука и сом, в меньшей степени представлены сазан, судак, окунь, присутствуют плотва, осетр, севрюга, стерлядь. Рыба вылавливались преимущественно среднего и крупного размера. Максимальное количество выловленных особей достигло возраста 8-10 лет. Выдвинуто предположение о способах рыбного промысла с помощью крючков, гарпунов, сетей, верш и заколов. Время бытования анализируемых материалов - вторая половина IV тыс. до н.э. Полученные результаты будут уточняться по мере дальнейшего изучения поселения.

Ключевые слова: лесостепное Поволжье; поздний энеолит; археозоология; комплексное исследование; поселение Лебяжинка VI; керамика с «внутренним ребром»; костяной крючок-блесна; составной крючок; гарпун; рыбный промысел; промысловые виды; щука; сом; сазан; судак; окунь; плотва; осетр; севрюга; стерлядь.

Актуальность темы определяется тем, что археозоологические исследования остеологических материалов в течение последнего десятилетия становятся неотъемлемым этапом изучения археологических памятников. Так, на основании археозоологических исследований возможно реконструировать палеоклиматические, палеоэкологические и палеоэкономические условия древних поселений и целых регионов, получить фаунистические данные по распространению видов в разные эпохи, выявить морфологические особенности животных, степень и причины их изменчивости во времени $[1 ; 2]$. Для лесостепного Поволжья такие исследования затруднены в силу того, что в культурном слое обычно не сохраняется органика. Большая часть стоянок многослойные с невыраженной стратиграфией, редки жилищные котлованы, отсюда сложность соотнесения фаунистических остатков с соответствующими комплексами. До недавнего времени исключением в этом плане являлось поселение Лебяжинка III, здесь было получено 17 костей рыб: сома, осетровых, окуня, а также рыболовные крючки и гарпуны [3, с. 187-188]. В последние годы особое значение приобрели материалы поселения Лебяжинка VI, где была получена представительная выборка костей рыб. Необходимо подчеркнуть, что выявленные здесь материалы, за единичным исключением, относятся к эпохе энеолита. На памятнике ведется изучение жилищных котлованов $1-4$. В заполнении сооружений 1-3 развалами залегает керамика основной группы (керамика с «внутренним ребром»), обширный каменный и костяной инвентарь, кости животных, черепах, птиц, рыб. Специфика культурного слоя способствовала хорошей сохранности органических остатков. Следует подчеркнуть, что большая часть костей рыб была получена при расчистке развалов сосудов с «внутренним ребром», в нижней части заполнения жилища, в приочажном пространстве, в очагах, в хозяйственных ямах. Наряду с костями диких животных, впервые в материалах энеолитических поселений региона, получены кости домашних видов [4, с. 254-258]. Имеющиеся даты, полученные по однотипной с керамикой с «внутренним ребром» посуде стоянки Чекалино IV, позволяют наметить время существование поселка в пределах второй половины IV тыс. до н.э.

Для решения вопросов хозяйства в энеолите лесостепи особый интерес представляет комплекс находок, связанных с рыбным промыслом, и данная статья посвящена анализу костей рыб, крючков и гарпунов, полученных в ходе раскопок 2013-14 гг.

Maтериаль и методbl. Орудия лова и охоты на рыбу включают однозубые, двузубые и многозубые гарпуны, цельные и составные крючки. Двузубый гарпун происходит из заполнения нижней части жилищного котлована 1 (рис. 1,6). Длина гарпуна 8,4 см, ширина в центре с зубцом 1,8 см, ширина насада
1,7 см, толщина 0,7 см. Насад по ребрам снабжен тремя неглубокими прорезями для крепления (следы резки сохранились). На поверхности следы тонкой абразивной обработки в диагональном и поперечном направлении, выступающие части заполированы. Однозубый гарпун располагался в развале сосуда с «внутренним ребром», его длина 6,2 см, ширина насада, 1,3 см, в центре - 1,1 см, толщина 0,6 см (рис. 1, 1). Поверхность заполирована до блеска, но сохранились поперечные и диагональные следы абразивной обработки. Насад содержит две мелкие выемки для крепления. От третьего гарпуна сохранился фрагмент острия с двумя зубцами (рис. 1,2 ). Его длина 5,8 см, ширина с зубцом $1,5 \mathrm{~cm}$, толщина $0,7 \mathrm{~cm}$. Он хорошо зашлифован, но заметна абразивная обработка в поперечном направлении. Был найден в заполнении основания котлована жилище 1. Обломок гарпуна происходит из культурного слоя (рис. 1, 9). Насад ассиметричный, у основания расширения мелкая прорезь. Длина фрагмента 4,9 см, ширина насада $1,1 \mathrm{~cm}$, толщина $0,6 \mathrm{~cm}$.

Крючок цельный с обломанной головкой для крепления и, частично, жалом найден в яме, в пределах котлована жилища 1 (рис. 1, 3). Длина изделия 6,1 см, ширина 2,1 см, толщина 0,9 см. Сохранилась абразивная обработка поверхности в горизонтальном и диагональном направлении.

Крючок цельный с обломанным жалом располагался в основании заполнения котлована постройки 4 (рис. 1, 4). Длина 4,7 см, ширина сохранившейся части 1,5 см, толщина 0,7 см. Хорошо заполирован, цевье заужено к головке, которая оформлена двумя кольцевыми прорезями для привязывания.

Крючок цельный с широким цевьем найден в культурном слое за пределами жилища (рис. 1, 5). Длина 3,7 см, ширина 1,7 см, часть головки и жальце обломаны. Прорези для крепления на головке крючка были нанесены с двух сторон с отступом в 0,3 см. Частично заполирован, но сохранились поперечные и диагональные следы абразивной обработки.

Цевье составного крючка располагалось в стороне от жилищ 1 и 2 (рис. 1, 7). Длина 6,6 см, ширина 0,7 см, толщина 0,4 см. В верхней части прорезаны две односторонние выемки для привязывания к леске, нижняя часть скошена под острым углом и содержит две аналогичные выемки для крепления со второй частью крючка - жальцем. Хорошо заметны диагональные следы обработки поверхности на абразиве, места крепления имеют блеск заполировки от использования.

На уровне пола постройки 3 были найдены вместе части составного крючка (рис. $1,8,10)$. Обе детали тщательно зашлифованы. Цевье с обломанной головкой длиной 6,7 см, шириной 0,9 см и толщиной 0,8 см для соединения с жалом срезано под острым углом, 
изготовлено из I колючего луча грудного плавника осетра (Acipenser guldenstaetii). Жало с обломанным острием и срезанным так же под острым углом основанием имеет длину 4,6 cм, ширину 0,6 см, толщину
0,4 см. Особенностью этого крючка является отсутствие прорезей для прочного соединения. Признанию деталей незавершенными заготовками мешает наличие сломов, как от бывших в употреблении орудий.
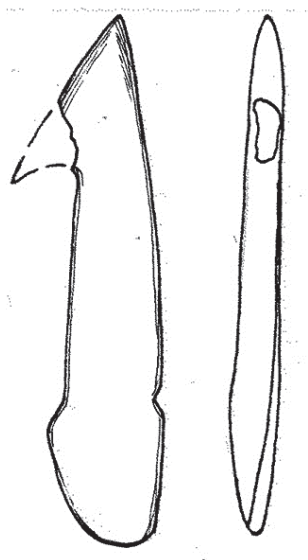

1
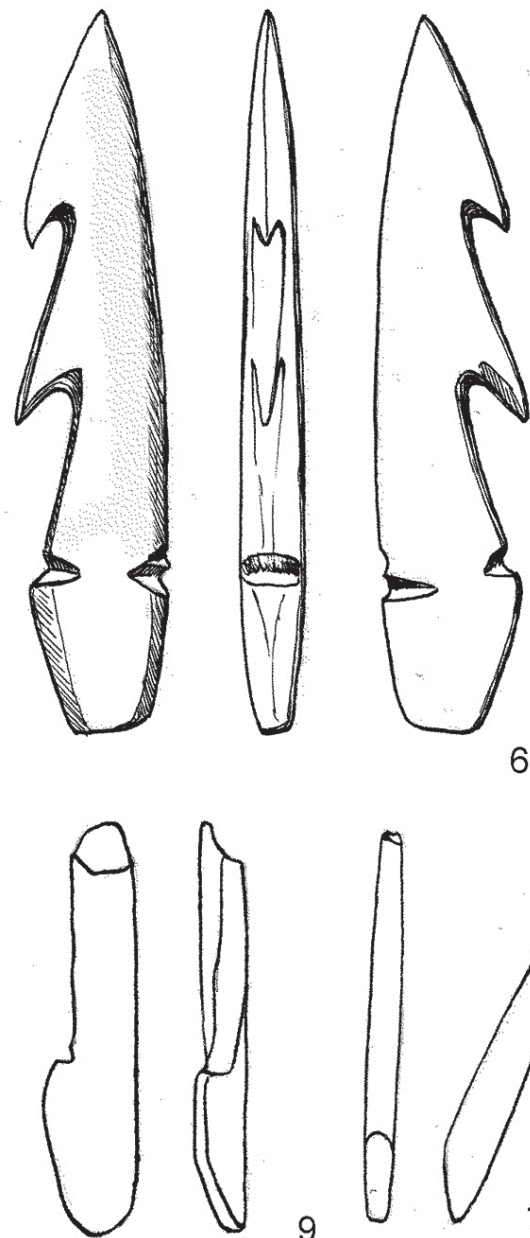

9

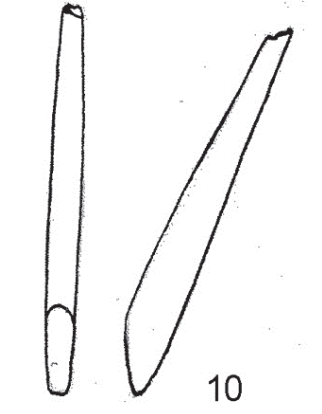

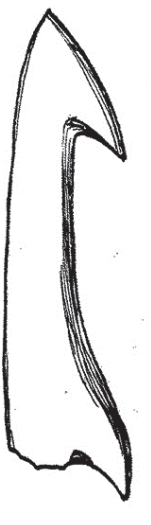

2
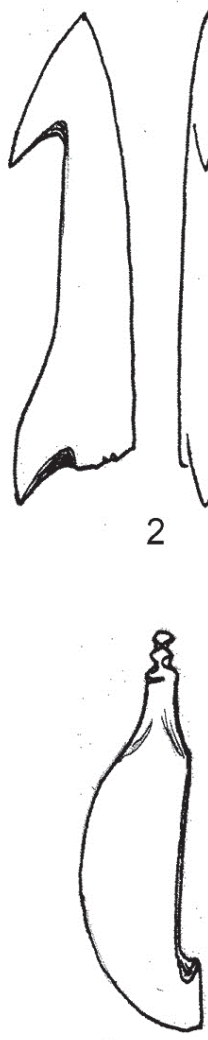

4
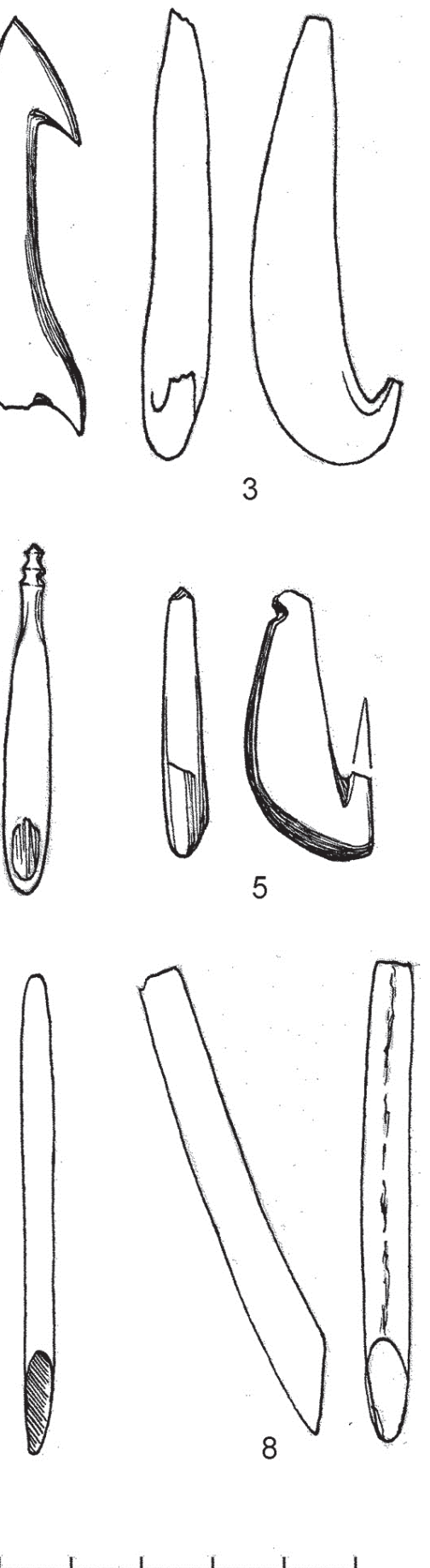

3
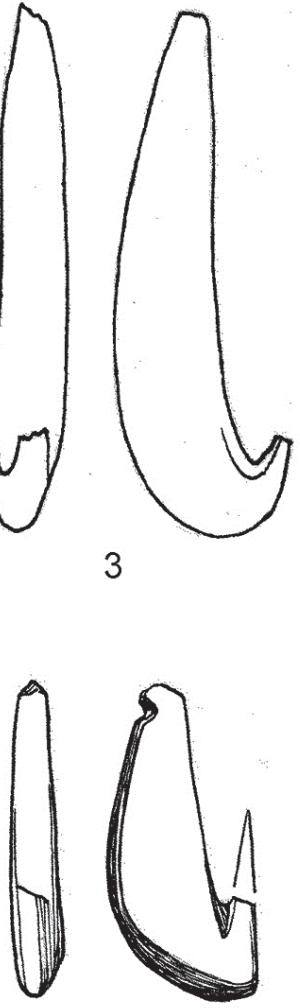

5

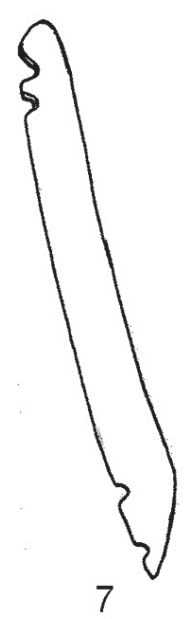

Рисунок 1 - Поселение Лебяжинка VI. Орудия рыбного промысла: 1, 2, 6, 9 - гарпуны;

$$
\text { 3-5, 7-10 рыболовные крючки }
$$

Таким образом, для ловли рыбы применяли крючки двух типов: цельные и составные. Цельные крючки изготавливались на широких заготовках из трубчатых костей, для них характерно широкое плоское цевье, выделенная прорезями головка, узкий острый изгиб и тонкое жало без бородки. Судя по размерам и широким пропорциям, они могли использоваться в качестве крючков-блесен для ловли крупной рыбы. Аналогичные изделия есть в коллекциях поселений Лебяжинка III [3, с. 187 , рис. $15 ; 2-4]$ и Гундоровка [5, с. 266 , рис. 26,9 , с. 269 , рис. $29,3-4]$. Типологическая близость таких крючков подкрепляется одинаковыми размерами и техникой изготовления. Определенное сходство просматривается также с крючками из I Хвалынского могильника, у которых круговой канавкой оформлена плоская головка и более округло выведен изгиб [6, с. 124 , рис. 28, 8-9]. Составные крючки для изучаемой территории оригинальны. На Гундоровском поселении найдена иная разновидность составного крючка с жалом снабженным бородкой [5, c. 266 , рис. 26, 2]. Оригинален и однозубый гарпун. Однорядный двузубый гарпун есть в коллекции Ива- 
новской стоянки, но он менее массивный, имеет приостренный насад, реже расставленные зубцы [7, c. 120 , рис. 15,8$]$, и более близок гарпуну из поселения Муллино [8, с. 257, табл. 116, 5].

Объем анализируемой выборки фаунистических остатков с данного памятника - 202 кости рыб. В данном случае 87 фрагментов (43,1\% от всех костных остатков) составили неопределимые кости, которые не являются диагностическими (ребра и позвонки), а также неопределимые ввиду значительной их раздробленности. Естественная сохранность материала 4 балла по 5-балльной шкале по методике Е. Антипиной [9].

Материал определен путем сравнения костных фрагментов с экземплярами современных и субфоссильных видов рыб из сравнительной остеологической коллекции Е.Ю. Яниш. Часть материала значительно фрагментирована, что существенно затрудняет определение до вида, а в ряде случаев и до отряда. Для вычисления размеров субфоссильных рыб кости измерялись штангенциркулем с точностью до 0,1 мм, затем по описанной В.Д. Лебедевым методике восстанавливалась длина и вес [10]. В тех случаях, когда это было возможно, точное определение возраста проведено по позвонкам.

При анализе результатов определений одна кость рыбы считается эквивалентной одному экземпляру, т.к. было доказано, что более одной кости от одной рыбы сохраняется крайне редко [10]. Систематика и латинские видовые названия рыб даны по определителю-справочнику Мовчана [11].

Результаты и обсуждения. В данном случае все кости рыб относятся к категории кухонных остатков, что косвенно подтверждается наличием обгорелых фрагментов черного цвета (кв. 17/17 - нижняя челюсть окуня; кв. 20/4 и 22/5 - позвонки щук; кв. 22/7 колючий луч грудного плавника; кв. 27/7 - клейтрум осетровой рыбы).

Цвет кости, подвергавшейся воздействию огня, позволяет узнать условия и температуру обжига, которому она подверглась. Так, черный цвет обожженных костей возникает при воздействии открытого пламени (например, костра) при температуре около 400-600 по Bradley [12]. Такая температура, как правило, достигается в костре или открытом очаге. При этом следует делать поправку, что эти данные были экспериментально получены для костей млекопитающих. Тогда как в виду разницы в структуре костной ткани и размерах самих костей, для рыб, вероятнее всего, будут несколько отличаться температурные режимы, при которых они приобретают черный цвет или становятся кальцинированными.

В исследованной коллекции преобладают остатки неосетровых рыб (94,1\% от всех остатков). Общая характеристика коллекции по объектам представлена в табл. 1.

Изучение видового состава показало, что всего в материале присутствуют 9 видов, относящихся к 5 отрядам: отряд Осетрообразные (Acipenseriformes) осетр русский (Acipenser gueldenstaedtii Brandt et Ratzeburg 1833), севрюга (Acipenser stellatus Pallas 1771), стерлядь (Acipenser ruthenus Linnaeus 1758); отряд Карповые - сазан (Cyprinus carpio Linnaeus 1758), плотва (Rutilus rutilus Linnaeus 1758), отряд Окунеоб- разные (Perciformes) - судак (Stizostedion lucioperca Linnaeus 1758), окунь (Perca fluviatilis Linnaeus 1758); отряд Щукообразные (Esociformes) - щука (Esox lucius Linnaeus 1758); отряд Сомообразные (Siluriformes) сом (Silurus glanis Linnaeus 1758).

Таблица 1 - Общие сведения о коллекции костей рыб поселения Лебяжинка VI

\begin{tabular}{|c|c|c|c|c|c|c|c|c|c|c|c|c|}
\hline \multirow[b]{3}{*}{$\begin{array}{l}\text { Участок / } \\
\text { горизонт }\end{array}$} & \multicolumn{12}{|c|}{ Виды рыб } \\
\hline & \multicolumn{6}{|c|}{$\begin{array}{c}\text { Костистые рыбы } \\
\text { (Teleostei) }\end{array}$} & \multicolumn{3}{|c|}{$\begin{array}{c}\text { Хряще- } \\
\text { вые га- } \\
\text { ноиды }\end{array}$} & \multicolumn{2}{|c|}{\begin{tabular}{|c|} 
Неоп \\
реде- \\
ли- \\
мые \\
\end{tabular}} & \multirow[b]{2}{*}{ : } \\
\hline & 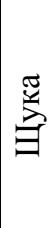 & ठ & 卺 & 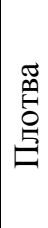 & 弆 & 己ै & 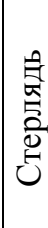 & 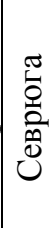 & : & 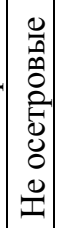 & $\begin{array}{l}0 \\
0 \\
0 \\
0 \\
0 \\
0 \\
0 \\
0 \\
0\end{array}$ & \\
\hline $26 / 1$ & & & 1 & & 1 & 1 & & & & 1 & & 4 \\
\hline $17 / 2$ & & & & & & & & & & 1 & & 1 \\
\hline $18 / 2$ & 1 & & & & & & & & & & & 1 \\
\hline $21 / 2$ & 1 & & & & & & & 1 & & 1 & & 3 \\
\hline $17 / 3$ & 9 & 2 & & & & & & 1 & & & & 12 \\
\hline $18 / 3$ & 1 & & & & & & & & & & & 1 \\
\hline $20 / 3$ & & & & & & & & & & 1 & & 1 \\
\hline $21 / 3$ & & 1 & & & & & & & & 1 & & 2 \\
\hline $25 / 3$ & 1 & & & & & & & & & & & 1 \\
\hline $14 / 4$ & & 1 & & & & & & & & & & 1 \\
\hline $17 / 4$ & 1 & 1 & & & & & & & & & & 2 \\
\hline $18 / 4$ & 1 & & & & & & & & & & & 1 \\
\hline $19 / 4$ & & & & & & & & & & 1 & & 1 \\
\hline $20 / 4$ & 2 & 1 & & & & & & & & 2 & & 5 \\
\hline $228 / 4$ & & & & & & & & & & 1 & & 1 \\
\hline $10 / 5$ & 1 & & & & & & & & & & & 1 \\
\hline $12 / 5$ & & & & & & & & & & 1 & & 1 \\
\hline $17 / 5$ & & & 1 & & & & & & & & & 1 \\
\hline $19 / 5$ & 3 & 1 & & & & & & & & 3 & & 7 \\
\hline $21 / 5$ & & & & & & & & & & 2 & & 2 \\
\hline $22 / 5$ & & & & & & & & & & 1 & & 1 \\
\hline $23 / 5$ & 1 & & 1 & & & & & & & & & 2 \\
\hline $24 / 5$ & 1 & 1 & & & & & & & & & & 2 \\
\hline $25 / 5$ & & & & & & & & & & 1 & & 1 \\
\hline $26 / 5$ & 1 & & & & & & & & & & & 1 \\
\hline $17 / 6$ & 2 & 3 & & & 1 & & & & & 2 & & 8 \\
\hline $18 / 6$ & 4 & 1 & & & & & & & & 1 & & 6 \\
\hline $19 / 6$ & 1 & 1 & & & & & & & & & & 2 \\
\hline $20 / 6$ & & 1 & & & & & & & & & & 1 \\
\hline $21 / 6$ & & & 1 & & & & & & & 1 & & 2 \\
\hline $24 / 6$ & 2 & 1 & & & & & & & & 1 & & 4 \\
\hline $26 / 6$ & 1 & 2 & 1 & & 2 & & & & & & & 6 \\
\hline $18 / 7$ & 1 & 2 & & & & & & & & 1 & 1 & 5 \\
\hline $21 / 7$ & & & 1 & & & & & & & 1 & 1 & 3 \\
\hline $25 / 7$ & & & & & & & & & & 1 & & 1 \\
\hline $27 / 7$ & & & & & & & & & & 1 & 1 & 2 \\
\hline $17 / 8$ & 1 & 2 & & & & 2 & & & & 6 & & 11 \\
\hline $17 / 8-74$ & & & & & & & & & & 2 & & 2 \\
\hline $18 / 8$ & & 1 & & & & & & & & 1 & & 2 \\
\hline $19 / 8$ & & 1 & & & & & & & & & & 1 \\
\hline $20 / 8$ & & & & & & & & & & 1 & & 1 \\
\hline $21 / 8$ & 1 & & & & & & & & 1 & 1 & & 3 \\
\hline $17 / 9$ & 2 & 1 & & & & & & 1 & & & & 4 \\
\hline
\end{tabular}


Королев А.И., Шалапинин А.А., Яниш Е.Ю.

07.00.00 - исторические науки и археология

\begin{tabular}{|c|c|c|c|c|c|c|c|c|c|c|c|c|}
\hline $17 / 9$ & & & & & & & & & & 4 & & 4 \\
\hline $19 / 9$ & 2 & & & & & & 1 & & & 1 & & 4 \\
\hline $21 / 9$ & 1 & & 1 & & & & & & & & & 2 \\
\hline $21 / 9$ & & & & & & & & & & 3 & & 3 \\
\hline $23 / 9$ & 1 & & & & & & & & & & & \\
\hline $29 / 9$ & & & & & & & & & & 1 & & 1 \\
\hline $13 / 10$ & 1 & & & 1 & & & & & & 2 & & 3 \\
\hline $17 / 10$ & & & & & & & & & & 1 & & 1 \\
\hline $21 / 10$ & 1 & & & & & & & & & 3 & & \\
\hline $22 / 10$ & & & & & & & & & & 2 & & \\
\hline $25 / 10$ & & & & & & & & & & 1 & & \\
\hline $27 / 10$ & 1 & & & & & & & & & & & \\
\hline $17 / 11$ & & & & & & & & & & 1 & & 1 \\
\hline $18 / 11$ & 1 & & & & & & & & & 1 & & \\
\hline $20 / 11$ & & & & & & & & & & 2 & & 2 \\
\hline $21 / 11$ & & & & & & & & & & 3 & & \\
\hline $22 / 11$ & & & & & & & & & & 4 & & 4 \\
\hline $22 / 12$ & 1 & 1 & & & & 1 & & & & & & 3 \\
\hline $25 / 12$ & 1 & & & & & & & 1 & & & & 2 \\
\hline $21 / 13$ & & & & & & & & & & 1 & & \\
\hline $22 / 13$ & & & & & & & & & 1 & & & 1 \\
\hline $17 / 17$ & 1 & 2 & & & 1 & 1 & & & 1 & 3 & 1 & 10 \\
\hline $18 / 17$ & & & & & & & & & & 1 & & \\
\hline $21 / 19$ & & 1 & & & 1 & & & & & & & 2 \\
\hline кв. 17 , яма & & 1 & & & & 1 & & & & & & 2 \\
\hline кв 26 яма & 1 & & & & & & & & & & & \\
\hline $\begin{array}{c}\text { кв 20/10 } \\
(-83), \text { в раз- } \\
\text { вале сосуда } \\
1 \text { группы }\end{array}$ & 2 & & & & & & & & & & & \\
\hline 24/12 яма & 3 & & & & & & & & & 1 & & 4 \\
\hline $27 /$ яма & 1 & & & & & & & & & 4 & & 5 \\
\hline $27 / 12$ яма & 1 & & & & & & & & & & & \\
\hline 27/12 яма & & & & & & & & & & 6 & & 6 \\
\hline $12 / 9$ & & & & & & 1 & & & & & & 1 \\
\hline Всего & 57 & 29 & 7 & 1 & 6 & 7 & 1 & 4 & 3 & \begin{tabular}{|l|}
83 \\
\end{tabular} & 42 & 202 \\
\hline
\end{tabular}

К изучению рыболовства в энеолите лесостепного Поволжья..

В ходе исследований выявлено, что в материале присутствуют кости как краниального (CRA), так и посткраниального скелета (PCRA), при этом последние преобладают над первыми в соотношении 2,6 к 1. Это позволяет считать наиболее достоверным предположение о разделке пойманной рыбы перед приготовлением ее в пищу прямо на территории поселения [13].

При подготовке рыбы для длительного хранения или транспортировки (в некоторых случаях), как правило, отделяется голова. В результате краниальные кости или выбрасываются в яму на месте заготовки (и тогда в материале представлены почти исключительно кости краниума), или, наоборот, почти полностью отсутствуют, если археологический материал не с места заготовки, а из участков, где непосредственно рыба была съедена. На первом месте по абсолютному количеству костей в материале щука $-28,2 \%$ от всех костей рыб ( $\mathrm{n}=57)$, на втором месте сом $-14,4 \%$ ( $\mathrm{n}=$ $29)$, сазан, судак и окунь практически в равном количестве (первые два вида - по 7 костей $(3,5 \%)$, окунь 6 (2,9\%), все остальные виды, включая осетровых, представлены единичными экземплярами. При расчете процента от всех определенных до вида рыб, значения несколько отличаются, но в целом соотношение видов сохраняется. Эти выводы предварительные, так как выборка незначительна и для проверки необходимы дальнейшие исследования поселения Лебяжинка VI.

В тех случаях, когда это было возможно, нами определен возраст рыб (табл. 2). Так, всего выявлено 17 возрастных категорий, точный возраст отдельных особей определен по позвонкам $(\mathrm{n}=61)$. Максимальное количество особей приходится на 8-10 летние экземпляры $(45,9 \%)$. Для щуки лов приходится на 8-9летние экземпляры, для сома - на 20-летние. Для сазана распределение более равномерное, кроме того значительное влияние оказывает маленькая выборка позвонков этого вида.

Таблица 2 - Возрастной состав рыб поселения Лебяжинка VI

\begin{tabular}{|c|c|c|c|c|c|c|c|c|c|c|c|c|c|c|c|c|c|c|}
\hline \multirow{2}{*}{ Виды } & \multicolumn{18}{|c|}{ Возраст, лет } \\
\hline & $5+$ & $6+$ & $7+$ & $8+$ & $9+$ & $10+$ & $11+$ & $12+$ & $13+$ & $14+$ & $15+$ & $16^{+}$ & $19+$ & $20+$ & $21+$ & $22+$ & $23+$ & Всего \\
\hline Щука & 2 & 1 & 4 & 9 & 9 & 8 & 3 & 1 & 1 & & & & & & & & & 38 \\
\hline CoM & & & & & & 1 & 1 & 1 & 1 & 2 & 1 & 3 & & 4 & 1 & 1 & 1 & 17 \\
\hline Сазан & & & & & & 1 & & 1 & 1 & 1 & & & 1 & & 1 & & & \\
\hline Всего & 2 & 1 & 4 & 9 & 9 & 10 & 4 & 3 & 3 & 3 & 1 & 3 & 1 & 4 & 2 & 1 & 1 & 61 \\
\hline
\end{tabular}

Кроме того, для щуки, сома и сазана нами высчитаны темпы роста. В результате исследования мы высчитали, что годовой прирост позвонка (табл. 3) современной щуки (по нашим данным) составляет 2,0 мм/год, тогда как значения этого показателя для субфоссильной щуки колебались от 0,8 до 1,6 мм в год, $(\mathrm{n}=35 ; \mathrm{M}=1,3 \pm 0,003$ мм/год). Средний годовой прирост позвонка субфоссильного сома из исследуемого памятника колеблется от 0,8 до $1,5 \mathrm{~mm} /$ год $(\mathrm{n}=13 ; \mathrm{M}=1,2 \pm 0,004$ мм/год), тогда как это показатель для современного сома составляет 1,5 мм/год. Для сазана средний годовой прирост позвонка колеблется от 1,0 до 1,4 мм/год (n=5; $\mathrm{M}=1,2 \pm 0,007$ мм/год), тогда как это показатель для современного сазана составляет 1,8-1,9 мм/год. Полученные данные подтверждают исследования В. Лебедева [10], который в своей монографии указывал, что раньше рыбы были более тугорослые, чем современные, что в первую очередь связано с качеством кормовой базы и влиянием со стороны человека.

В результате анализа остеологического материала нами реконструированы средняя длина тела, вес и возраст рыб в тех случаях, когда это было возможно (табл. 4). Основную часть добытых на поселении рыб составляют половозрелые особи средних и крупных размеров. Наличие щуки, сома, судака и окуня от 24 до 36 см указывает на то, что использовались методы, позволяющие добыть и более мелкие экземпляры.

Все зарегистрированные нами виды относятся к двум фаунистическим комплексам [14]: верхнетретичному (сом, судак, сазан, осетр, севрюга, стерлядь), а также бореальному равнинному (щука, окунь, плотва). Исходя из характеристик фаунистических комплексов и видового состава рыб данного памятника, 
мы можем предположить, что в исследуемый период вода реки, возле которой располагалось поселение, содержала достаточное количество кислорода для обитания оксифильных видов (осетровых), обладала относительной прозрачностью и не быстрым течением.

Таблица 3 - Годовой прирост позвонка у субфоссильных видов рыб (мм/год)

\begin{tabular}{|c|c|c|c||c|c|c|c|}
\hline \multirow{2}{*}{ № экз. } & \multicolumn{3}{|c||}{ Виды № экз. } & \multicolumn{3}{|c|}{ Виды } \\
\cline { 2 - 7 } & Щука & Сом & Сазан & & Щука & Сом & Сазан \\
\hline 1 & 1,3 & 1,1 & 1,2 & 19 & 1,3 & & \\
\hline 2 & 1,2 & 1,2 & 1,3 & 20 & 1,0 & & \\
\hline 3 & 1,6 & 1,2 & 1,0 & 21 & 1,3 & & \\
\hline 4 & 1,3 & 1,3 & 1,0 & 22 & 1,4 & & \\
\hline 5 & 1,2 & 1,2 & 1,4 & 23 & 1,5 & & \\
\hline 6 & 1,2 & 1,5 & & 24 & 1,3 & & \\
\hline 7 & 1,2 & 1,3 & & 25 & 1,5 & & \\
\hline 8 & 1,2 & 1,2 & & 26 & 1,3 & & \\
\hline 9 & 0,8 & 0,9 & & 27 & 0,1 & & \\
\hline 10 & 1,0 & 0,9 & & 28 & 1,2 & & \\
\hline 11 & 1,2 & 1,1 & & 29 & 1,4 & & \\
\hline 12 & 1,2 & 1,1 & & 30 & 1,3 & & \\
\hline 13 & 1,2 & 1,1 & & 31 & 1,3 & & \\
\hline 14 & 1,1 & & & 32 & 1,2 & & \\
\hline 15 & 1,1 & & & 33 & 1,2 & & \\
\hline 16 & 1,1 & & & 34 & 1,4 & & \\
\hline 17 & 1,2 & & & 35 & 1,3 & & \\
\hline 18 & 1,6 & & & & & & \\
\hline
\end{tabular}

Таблица 4 - Основные параметры рыб, реконструированные путем экстраполяции данных

\begin{tabular}{|c|c|c|c|c|c|c|c|}
\hline \multirow[b]{2}{*}{ Вид } & \multirow[b]{2}{*}{$\begin{array}{c}\mathrm{N} \\
\text { про- } \\
\text { меров }\end{array}$} & \multirow[b]{2}{*}{$\begin{array}{c}\mathrm{L} \\
\max , \\
\mathrm{cm}\end{array}$} & \multirow[b]{2}{*}{$\begin{array}{c}1 \\
\min , \\
\mathrm{cm}\end{array}$} & \multirow[b]{2}{*}{$\begin{array}{c}\mathrm{L} \\
\mathrm{cp}\end{array}$} & \multirow[b]{2}{*}{$\begin{array}{c}\text { Bec } \\
\text { cp., } \\
\text { Кг }\end{array}$} & \multicolumn{2}{|c|}{ Возраст } \\
\hline & & & & & & $\begin{array}{c}\text { Поло- } \\
\text { возре- } \\
\text { лые }\end{array}$ & $\begin{array}{l}\text { Непо- } \\
\text { лово- } \\
\text { зрелые }\end{array}$ \\
\hline Осетр & 1 & - & - & 90,0 & 7,3 & 1 & - \\
\hline Севрюга & 2 & 108,1 & 56,8 & 82,5 & 6,2 & 1 & 1 \\
\hline Стерлядь & 1 & - & - & 52,1 & 2,0 & 1 & - \\
\hline Щука & 42 & 103,3 & 33,6 & 70,5 & 1,0 & 42 & - \\
\hline CoM & 20 & 120,0 & 35,9 & 85,1 & 1,6 & 20 & - \\
\hline Судак & 4 & 58,8 & 25,9 & 40,6 & 0,45 & 4 & - \\
\hline Сазан & 7 & 126,8 & 76,2 & 95,8 & 4,1 & 7 & - \\
\hline Окунь & 4 & 36,7 & 24,5 & 28,3 & 0,3 & 4 & - \\
\hline Плотва & 1 & - & - & 24,0 & 0,36 & 1 & - \\
\hline
\end{tabular}

Так как остеологический материал представляет собой кухонные остатки, возможен перерасчет костных остатков рыб, добывавшихся на мясное потребление. Так, в мясном потреблении (вернее, в потреблении рыбы по массе) лидирует щука (32,8\%), на втором месте, почти в равном соотношении - сом и сазан ( $25,1 \%$ и $22,5 \%$ соответственно), далее идут осетровые (табл. 5).

Bblвoдbl. Остеологические материалы данного памятника относятся к категории «кухонные остатки». Всего в материале выявлено 3 вида осетровых (осетр, севрюга, стерлядь) и 6 видов костистых рыб (щука, сом, сазан, плотва, судак, окунь), которые и в настоящее время относятся к типичным видам ихтиофауны Волжско-Каспийского бассейна. Наличие в материале костей как краниального, так и посткраниального скелета свидетельствует о том, что рыба не доставлялась издалека, а добывалась относительно недалеко от поселения и разделывалась уже непосредственно перед употреблением в пищу. По предварительным результатам, основными промысловыми видами были щука, сом и сазан. Рыбы вылавливались преимущественно среднего и крупного размера, максимальное количество особей приходится на 8-10 летних рыб (45,9\%). Для щуки, сома и сазана высчитаны темпы роста. Полученные данные подтверждают большую тугорослость рыб в прошлом, что в первую очередь связано с качеством кормовой базы и влиянием со стороны человека.

Таблица 5 - Реконструкция усредненного соотношения мясного потребления видов

\begin{tabular}{|l|r|c|r|r|}
\hline \multicolumn{1}{|c|}{ Вид } & $\begin{array}{c}\text { Число } \\
\text { костей, } \mathrm{n}\end{array}$ & $\begin{array}{c}\text { Вес одной } \\
\text { средней } \\
\text { особи, кг }\end{array}$ & $\begin{array}{c}\text { Выход } \\
\text { мяса, кг }\end{array}$ & \multicolumn{1}{c|}{$\%$} \\
\hline Осетр & 1 & 7,3 & 7,3 & 5,7 \\
\hline Севрюга & 2 & 6,2 & 12,4 & 9,7 \\
\hline Стерлядь & 1 & 2,0 & 2,0 & 1,6 \\
\hline Щука & 42 & 1,0 & 42,0 & 32,8 \\
\hline Сом & 20 & 1,6 & 32,0 & 25,1 \\
\hline Судак & 4 & 0,5 & 1,8 & 1,4 \\
\hline Сазан & 7 & 4,1 & 28,7 & 22,5 \\
\hline Окунь & 4 & 0,3 & 1,2 & 0,9 \\
\hline Плотва & 1 & 0,4 & 0,4 & 0,3 \\
\hline Всего & 82 & - & 127,7 & 100,0 \\
\hline
\end{tabular}

Реконструированные размеры субфоссильных рыб, а также находки гарпунов, крючков и грузил позволяют предположить, что ловля преимущественно происходила сетями и крючными снастями. Наличие рыб длиной до 36 см косвенно указывает на то, что могли использоваться верши, заколы и т.д., которые почти не оставляют археологических следов. Исходя из характеристик фаунистических комплексов и видового состава рыб данного памятника, мы можем предположить, что в исследуемый период вода реки, возле которой располагалось поселение, содержала достаточное количество кислорода для обитания оксифильных видов (осетровых), обладала относительной прозрачностью и не быстрым течением.

Для более полных выводов необходимы дальнейшие исследования данного памятника, а также сравнение с материалами других археологических памятников исследуемого периода.

\section{СПИСОК ЛИТЕРАТУРЫ:}

1. Яніш Є.Ю. Археозоологія - дисципліна на межі наук // Вісник Академії наук України, 2016.

2. Яніш С.Ю. Археозоологія - галузь на межі наук // Зоологічний кур'єр. Тези доповідей Конференції молодих долідників-зоологів-2015, Київ, 2015, № 9, C. 41.

3. Овчинникова Н.В. Лебяжинка III - поселение эпохи энеолита в лесостепном Заволжье // Древние культуры лесостепного Поволжья (к проблеме взаимодействия индоевропейских и финно-угорских культур. Самара: Изд-во СамГПУ, 1995. С. 164-191.

4. Королев А.И., Рослякова Н.В. Хозяйственная деятельность в энеолите лесостепного Поволжья (по материалам поселения Лебяжинка VI) // Археология озерных поселений IV-II тыс. до н.э.: хронология культур и природно-климатические ритмы: материа- 
лы международной конференции. СПб.: Эрмитаж, 2014. С. 254-258.

5. Васильев И.Б., Овчинникова Н.В. Энеолит // История Самарского Поволжья с древнейших времен до наших дней. Каменный век. Самара: Изд-во СНЦ PAH, 2000. $310 \mathrm{c}$.

6. Агапов С.А., Васильев И.Б., Пестрикова В.И. Хвалынский энеолитический могильник. Саратов: Изд-во Саратовского гос. ун-та, 1990. 160 с.

7. Моргунова Н.Л. Ивановская стоянка эпохи неолита-энеолита в Оренбургской области // Энеолит Восточной Европы. Куйбышев, Изд-во КГПИ, 1980. C. 104-124.

8. Матюшин Г.Н.Энеолит Южного Урала. М.: Наука, 1982. 328 с.

9. Антипина Е.Е. Археозоологические исследования: задачи, потенциальные возможности и реальные результаты // Новые археозоологические исследования в России, Москва: Изд-во Языки славянской культуры. 2003. С. 7-34.
10. Лебедев В.Д. Пресноводная четвертичная ихтиофауна Европейской части СССР. М.: Изд-во МГУ, 1960. 404 c.

11. Мовчан Ю.В. Риби України. К.: Изд-во Золоті ворота, $2011.420 \mathrm{c}$.

12. Bradley R. The Moon and the Bonfire. An investigation of three stone circles in northeast Scotland. Edinburgh: Society of Antiquaries of Scotland. 2005. 124 p.

13. Яниш Е.Ю., Антипина Е.Е. Промысловые рыбы древней Ольвии (I-III вВ. н.э.) и ее окрестностей // Зоологический журнал, 2013, Т. 92, № 9. С. 11901200.

14. Никольский Г.В. О биологической специфике фаунистических комплексов и значении их для зоогеографии // Очерки по общим вопросам ихтиологии. М.: Л.: Изд-во АН СССР, 1953. С. 65-67.

Работа выполнена при финансовой поддержке Министерства образования и науки РФ (госзадание $33.1195 .2014 / \kappa)$.

\title{
FISHERY IN THE ENEOLITHIC FOREST-STEPPE OF THE VOLGA REGION (ON EXCAVATION MATERIALS OF LEBYAZHINKA VI SETTLEMENT IN 2013-2014 YEARS)
} (C) 2016

\author{
A.I. Korolev, candidate of history sciences, dean of History Faculty, \\ associate professor of Domestic History and Archaeology Department \\ A.A. Shalapinin, candidate of history sciences, researcher of Scientific Department \\ Samara State University of Social Sciences and Education, Samara (Russia) \\ E.Y. Yanish, candidate of biological sciences, junior researcher of Animal Monitoring and Conservation Department \\ I.I. Schmalhausen Institute of Zoology, Kiev (Ukraine)
}

\begin{abstract}
The following paper contains information about fishers' weapons and fish bones founded in Lebyazhinka VI eneolitic settlement in the forrest-steppe region of the Volga river. We analyse materials of the second half of the IV millennium BC. The filling of pits represents dwellings with the «inner edge», stone and bone tools, animal bones of turtles, birds and fish. The importance of this studiing is in the possibility of a complex view. The purpose of this article is to analyze the fish catching, hunting and fish bones. Hunting tools are represented by bone harpoons with one, two or many teeth, arranged on one side. There are two types of fishbone hooks: whole and composite. We determined the typological features of catching tools, and moreover we determined quantitative, species, age and size characteristics of fish. The main fishes were pike and catfish, then luce, pike, perch, roach, sturgeon, sterlet. The fish sizes are medium and large, the age is about 8-10 years. We have an opinion of the way of fishing including hooks, harpoons, nets and stakes. The research will be completed with new materials.

Keywords: forrest-steppe region; late eneolite; archezoology; complex study; Lebyazhinka VI; eneolithic settlement; dwellings with the «inner edge»; bone hook-lure; composite hook; harpoon; fishing; pike and catfish; luce; pike; perch; roach; sturgeon; sterlet.
\end{abstract}

УДК 902.903 .023

\section{КРУПНОТАРНЫЕ СОСУДЫ БРОНЗОВОГО ВЕКА ТУРГАНИКСКОГО ПОСЕЛЕНИЯ В ОРЕНБУРГСКОЙ ОБЛАСТИ}

(C) 2016

Н.П. Салугина, кандидат исторических наук, доцент кафедры теории и истории культуры Самарский государственный институт культуры, Самара (Россия)

Н.Л. Моргунова, доктор исторических наук, профессор, заведующий археологической лабораторией Оренбургский государственный педагогический университет, Оренбург (Россия)

М.А. Турецкий, кандидат исторических наук, старший научный сотрудник

Поволжский филиал Института российской истории РАН, Самара (Россия)

Аннотация. В керамической коллекции Турганикского поселения в Оренбургской области выделяется группа керамики эпохи бронзы, которая по своим морфологическим и технологическим показателям резко выделяется из основной группы посуды. Это сосуды крупных размеров с массивными венчиками и раздутым туловом. Авторы условно назвали эти сосуды хумами. Задачей данного исследования является попытка определить культурно-хронологическую позицию указанной группы посуды в системе древностей раннего - среднего бронзового века. Внутри этой группы авторы выделяют два типа. Основанием для выделения типов послужили 